\title{
Prediction of changes in groundwater dynamics caused by relocation of river embankments
}

\author{
Ulf Mohrlok
}

Institute for Hydromechanics, Kaiserstrasse 12, D-76128 Karlsruhe

Email: mohrlok@ifh.uka.de

\begin{abstract}
Ecosystems in river valleys are affected mainly by the hydraulic conditions in wetlands including groundwater dynamics. The quantitative prediction of changes in groundwater dynamics caused by river embankment relocation requires numerical modelling using a physicallybased approach. Groundwater recharge from the intermittently flooded river plains was determined by a leakage approach considering soil hydraulic properties. For the study area in the Elbe river valley north of Magdeburg, Germany, a calibrated groundwater flow model was established and the groundwater dynamics for the present situation as well as for the case of embankment relocation were simulated over a 14-year time period. Changes in groundwater depth derived from simulated groundwater levels occurred only during flood periods. By analysing the spatial distributions of changes in statistical parameters, those areas with significant impact on the ecosystems by embankment relocation can be determined.
\end{abstract}

Keywords: groundwater dynamics, groundwater recharge, flood plains, soil hydraulic properties, numerical modelling, river embankment relocation

\section{Introduction}

Wetlands in river valleys are very important for ecosystems preferring wet site conditions. These ecosystems are well adapted to the specific hydrological conditions within the wetland, which are determined by the flood events, in particular the season of occurrence, the frequency and the duration of flooding. Additionally, it is accepted that groundwater dynamics have great importance for these ecosystems. Groundwater depth also has a significant impact on the soil water budget and, therefore, on the habitat conditions of certain plants (Blom et al., 1996). Since the groundwater level is near the land surface, evapotranspiration from groundwater also plays an important role in the wetland water budget (Acreman et al., 2002; Truebinger et al., 2002; Weng et al., 2002).

Recently, to reduce the risk of flood disasters and restore wetland areas and their associated ecosystems (Jährling, 1994), several attempts have been made to propose river embankment relocations along large rivers like the Elbe in Germany. Such human activities will affect the present ecosystems and the assessment of these changes requires an understanding of the hydrological and hydraulic processes and their interactions determining those ecosystems. Furthermore, quantitative comparison of the impact of different scenarios, for instance for embankment relocation, requires the application of numerical models with predictive capability describing those processes.

The main hydraulic process determining groundwater dynamics in riverine wetlands is infiltration from the river banks and from the intermittently flooded river plains (e.g. Winter, 1995). In particular, flood-plain infiltration may cause considerable groundwater recharge depending on the soil hydraulic properties and the surface area affected. Relocating river embankments will enlarge this surface area enormously and this will affect the groundwater dynamics significantly. Through analysis of single flood events, those processes have been simulated numerically by a finite element approach solving the transient equations for the unsaturated and saturated flow simultaneously in twodimensional vertical cross sections for different transects (Bates et al., 2000).

However, to quantify groundwater dynamics on a regional scale for long-term periods, it is necessary to apply a transient two- or three-dimensional groundwater flow model 
and to consider infiltration from intermittently inundated flood-plains in detail. In this paper a method is presented that can predict changes of groundwater dynamics resulting from expansion of flood-plain areas due to river embankment relocation. A physically-based approach, which incorporates the spatial distribution of soil hydraulic properties, has been developed that defines the groundwater recharge from the flood plains as a leakage boundary condition in the regional groundwater flow model (Mohrlok et al., 2000). By statistical analyses of the computed time series of groundwater level and groundwater depth, physical variables affecting the wetland ecosystems have been included. Those variables could be used to assess the impact of embankment relocation on wetland ecosystems. The case study presented is the first application of this method.

\section{Groundwater modelling}

\section{STUDY AREA}

The research presented was carried out in a study area in the Elbe river valley, $15 \mathrm{~km}$ north of Magdeburg, Germany. This site covered the whole river valley about $10 \mathrm{~km}$ in length upstream of the confluence of the tributary Ohre with the Elbe (Fig. 1). The relocation of a river embankment close to the confluence has been proposed (Jährling, 1994) for the purpose of expanding the retention area and restoring the wetland. However, only a small part of the flood plain within the study area could be characterised as wetland because of the depth of the groundwater in most parts. The hydrology is dominated by the dynamics of river discharge and the corresponding water level of the Elbe. Flood periods occur mainly in winter and spring time following precipitation and snow melt in the River Elbe catchment. Catchment hydrology of the tributary Ohre is dominated by local precipitation events. This factor causes backwaters in the Ohre close to the confluence with the Elbe during flood events. Recorded time series of the water levels in the Elbe and Ohre were available from several river gauging stations to compute the time series for the boundary conditions of the numerical groundwater flow model.

Hydrogeological characteristics were used to delineate the model boundary of the study area. The shallow alluvial aquifer consists of fluvio-glacial deposits of sand and gravel dating from the last glacial period, about 10,000 years ago. Sandy soils and marly sediments from former glacial periods form the geology of the present river valley. The aquifer thickness varies greatly from a few metres in the north-east to 40 metres in the south-west of the study area. The main groundwater flow in the valley is affected by the movement of water between the rivers and the intermittently flooded river plain. The direction of water movement depends on the hydrological conditions. Additionally, there is a significant inflow from the geological formations marking the border lines of the study area due to their importance as recharge areas. High recharge rates within the study area result only from significant precipitation events in winter and spring.

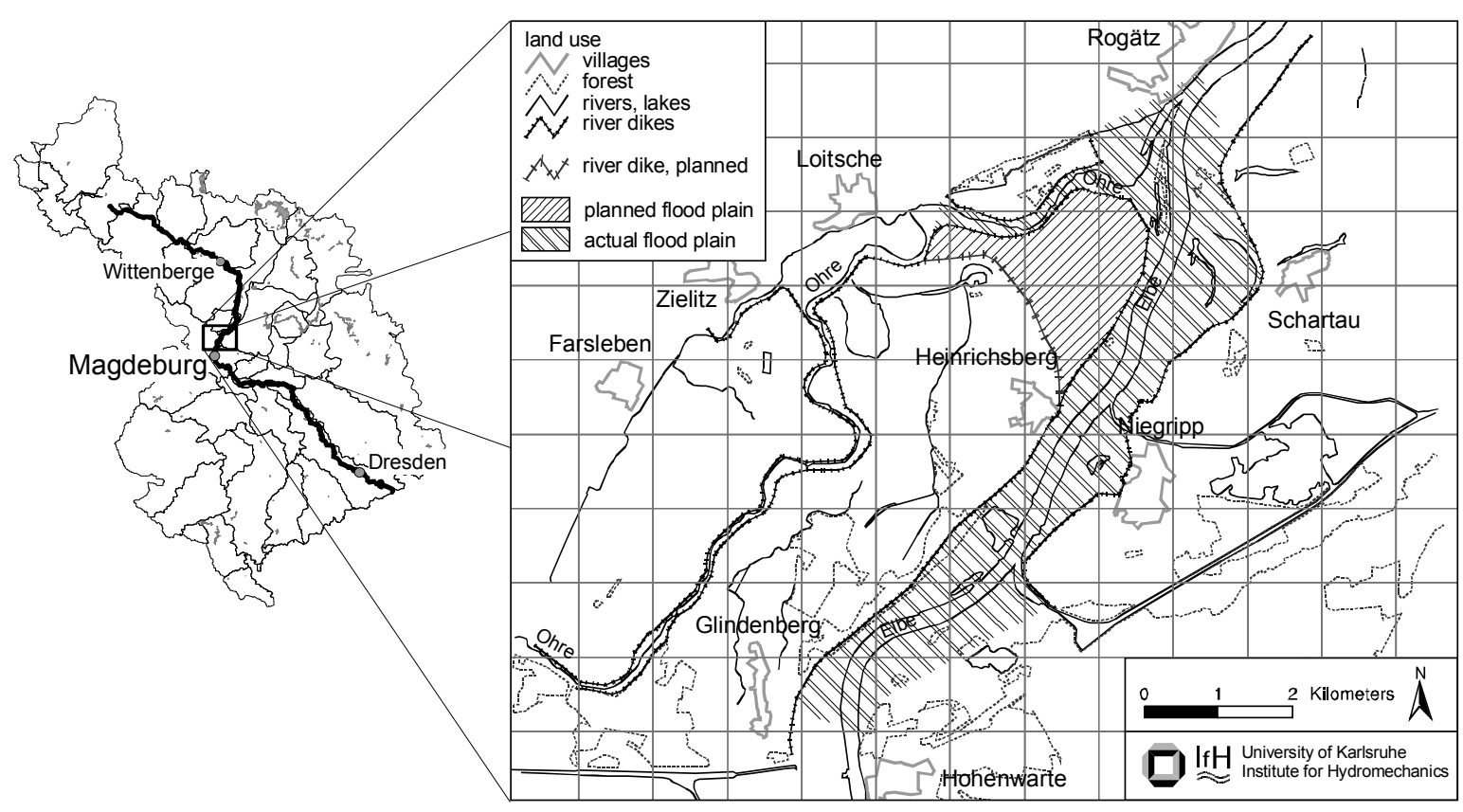

Fig. 1. Study area at the Elbe river valley north of Magdeburg, Germany. 
To estimate infiltration rates from the intermittently inundated flood plains, detailed investigations of soil hydraulic properties were carried out. Analysis of the topography, resulting from landscape history, distinguishes eight different soils related to the morphologic development of the River Elbe. Soil thickness was available for the area of planned embankment relocation (Rommel, 1998). Soil profiles have been investigated in detail at sites selected as representative for each soil. Two to four horizons, with varying hydraulic properties, could be distinguished at those soil profiles. Soil samples of every horizon were taken to the laboratory for further analyses of the texture and hydraulic properties (Mohrlok et al., 2000).

There were only a few long-term groundwater monitoring wells run by the State of Saxony-Anhalt within the study area (Fig. 2). Their data were used to define the model boundary conditions. Ten additional groundwater monitoring wells (GWMKA_01 to GWMKA_10) were installed at selected locations (Fig. 2) to determine the variability of groundwater level within the study area. Time series were obtained over the period November 1997 to October 1999 and served as a basis for model calibration.

\section{NUMERICAL MODEL SET UP}

Transient groundwater flow in the shallow unconfined aquifer of the study area was simulated using the finite element code HFLOW_HT, developed at the Institute for Hydromechanics, University of Karlsruhe (Herrling, 1982). The model domain was defined with respect to the hydrogeological features of the study area and covered the whole width of the Elbe river valley with its extension limited by cross sections where the Elbe river meets the valley margins. The finite element discretisation of the model domain comprised 7772 nodes and 15402 trianglar elements. The orientation of the element edges was aligned with relevant water bodies and river embankment margins.

Boundary conditions were determined by the hydrogeology of the region (Fig. 2). Inflow boundaries were established at the Elbe river valley margins due to the adjacent groundwater recharge areas. In the south-east, the inflow time series to the model boundary was determined by the estimated discharge from the recharge area, whereas the inflow to the model boundary to the north-west was defined by a leakage approach using the recorded groundwater level time series from monitoring well

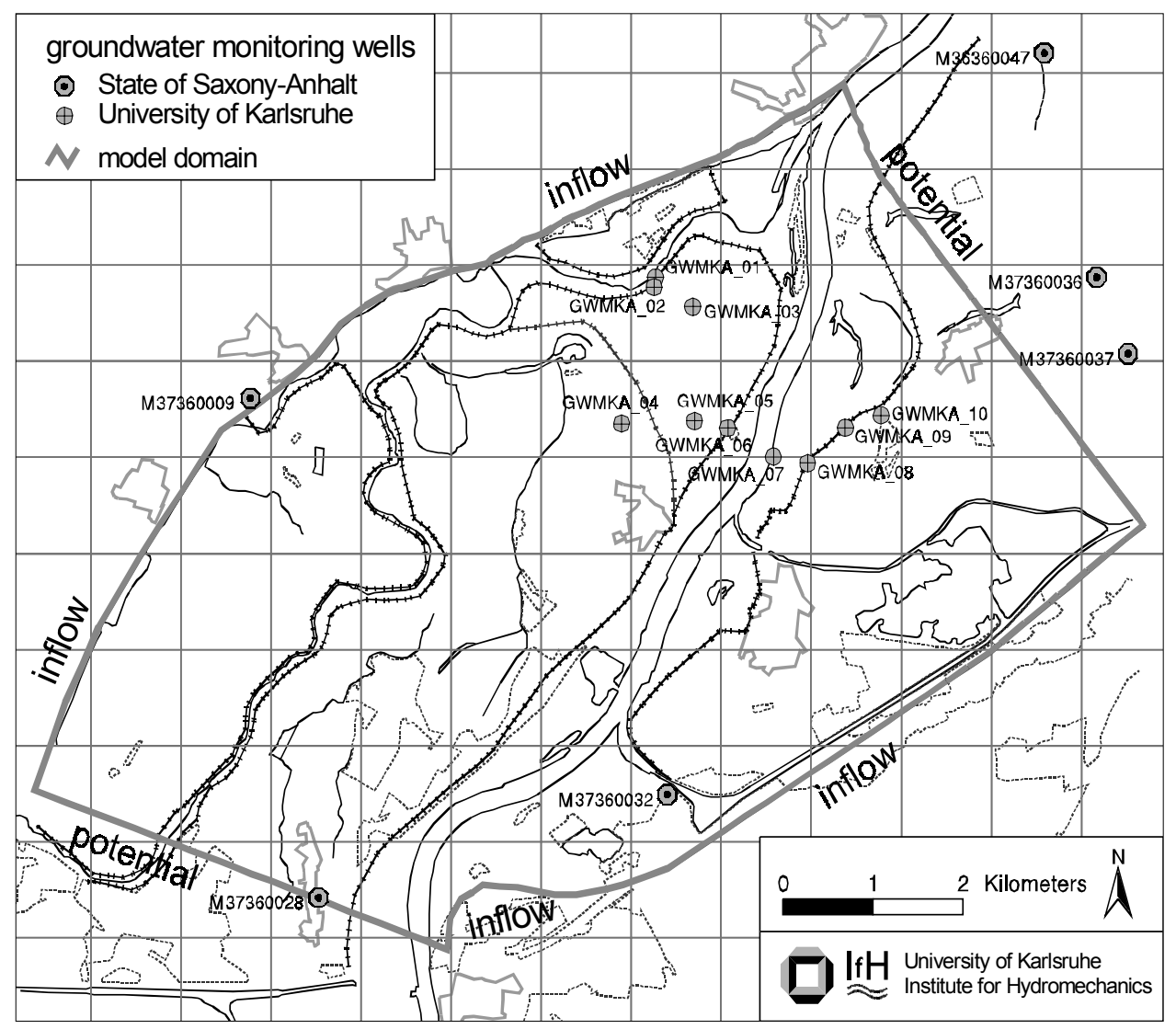

Fig. 2. Numerical model domain, definition of boundary conditions and locations of groundwater monitoring wells. 
M37360009. The potential boundary conditions at the boundaries perpendicular to the valley were derived from recorded time series of state monitoring wells, M37360028 in the south and M36360047, M37360036 and M37360037 in the north. Recharge from deeper aquifers was neglected due to the specific hydrogeological conditions, in that discharge from deeper aquifers enters the shallow aquifer via a regional fault zone south of the study area.

The Elbe river and its tributary Ohre were incorporated into the model as leakage boundaries. The required time series of water levels were interpolated from the Elbe and Ohre water levels recorded daily at gauging stations within or near the area under investigation. Backwater zones in the Ohre tributary were calculated for periods of high-water levels according to monitored Elbe water levels near the confluence. The leakage parameters of the rivers were obtained by calibration.

The most important effect on changes in groundwater dynamics due to relocation of embankments is given by the recharge from the intermittently inundated flood-plain marked by the location of the river embankment. This recharge was implemented by leakage boundary conditions to guarantee the predictive capacity of the numerical model. The respective water levels were obtained by extrapolating the Elbe water levels to the flood plain areas. The leakage parameters characterising the soils were estimated by a physical approach (Mohrlok et al., 2000). The hydraulic properties of the distinct soil layers, i.e. porosity, hydraulic conductivity and parameters of the 'van Genuchten' retention relationship, were obtained by laboratory investigations of soil samples. These parameters were used for numerical computation of flux rates at different depths in each profile by analysing hypothetical flood events using the code SWMS (Simunek et al., 1994). The entire range of variability of infiltration rates was covered by these investigations and the spatial distribution of the leakage parameters was derived for the current situation as well as for the expanded flood plain area under a given scenario of river embankment relocation (Fig. 3). Time series of spatially distributed groundwater recharge from precipitation were considered with respect to different soils and land use.

\section{MODEL CALIBRATION}

The numerical groundwater model was calibrated by fitting the computed groundwater level time series to the measured time series at the monitoring wells GWMKA_01 to GWMKA_10 for the period of November 1997 until October 1999. The target of the calibration process was the determination of the unknown aquifer parameters. Hydraulic conductivity, effective porosity and the leakage parameters of the hydraulic contact of the Elbe and the tributary Ohre to the groundwater were quantified by calibration.

Each of the measured time series could be fitted very well

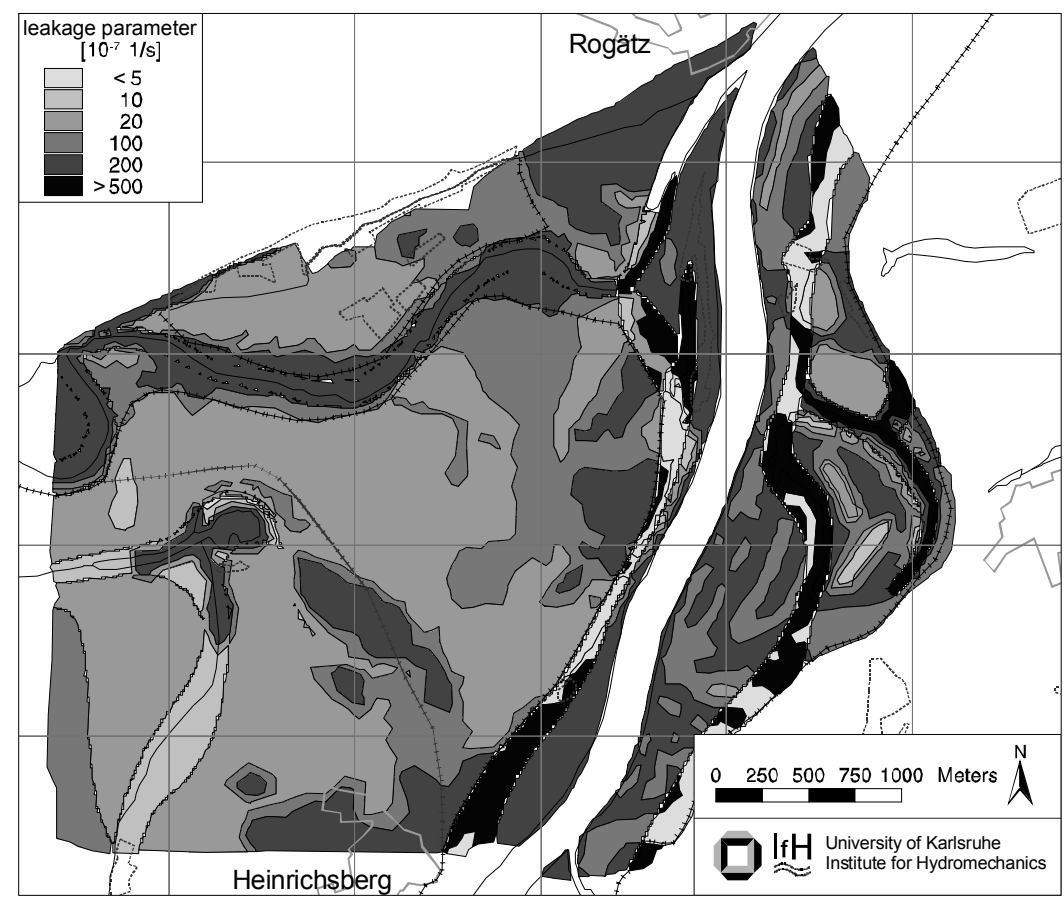

Fig. 3. Spatial distribution of the leakage parameters characterising the soils in the flood plains. 

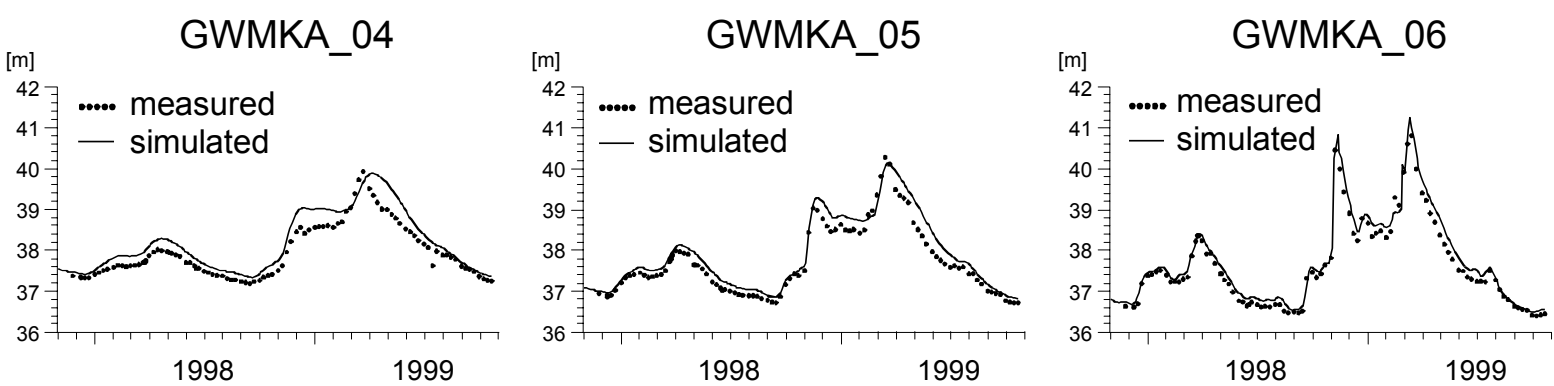

Fig. 4. Fitted ground water level time series at selected monitoring wells GWMKA_04, GWMKA_05 and GWMKA_06 as result of model calibration.

by the computed series. The average differences of the computed and measured groundwater levels were about $15 \mathrm{~cm}$. The increasing attenuation of the fluctuations of the groundwater levels at locations further from the river Elbe were predicted by the model (Fig. 4). In particular, the effect of infiltration from the intermittently inundated flood-plain on groundwater dynamics (e.g. at GWMKA_08) was reproduced very well.

A homogeneous hydraulic conductivity of $8.0 \cdot 10^{-4} \mathrm{~ms}^{-1}$ and a homogeneous effective porosity of 0.09 were obtained by the calibration. Saucke and Brauns (1999) determined an equivalent hydraulic conductivity of $8.0 \cdot 10^{-4} \mathrm{~ms}^{-1}$ as determined by detailed sieve analyses of soil samples from several boreholes in the study area. They found a similar effective porosity of about 0.07 by analysing small scale tracer tests. The leakage parameter of $2.5 \cdot 10^{-5} \mathrm{~s}^{-1}$, describing the hydraulic contact of the Elbe, was determined mainly by fitting the time series at GWMKA_07. That corresponds well to a river bed of medium sand $1-2 \mathrm{~m}$ thick. The leakage parameter of the tributary Ohre of $2.0 \cdot 10^{-5} \mathrm{~s}^{-1}$ was obtained by fitting the time series at GWMKA_01. This is consistent with a river bed consisting of fine to medium sand $0.5-1 \mathrm{~m}$ thick.

\section{Results}

To predict the changes in groundwater dynamics caused by river embankment relocation, two simulations were performed using this calibrated numerical model. The current situation was simulated using the actual river embankment positions, whereas in the case of river embankment relocation, an expanded flood plain close to the confluence of Ohre and Elbe was considered. Both simulations were undertaken for the same 14-year period from November 1985 to October 1999, for which boundary conditions could be defined continuously. Thus, the predicted changes of groundwater dynamics were caused only by hydraulics and not by global changes in hydrology.

Physical parameters describing the groundwater dynamics were derived by statistical time series analysis of the groundwater levels computed at every node of the finite element grid. Average values, their fluctuations, extreme values and duration curves were calculated from those groundwater level time series. Spatial changes in groundwater dynamics were analysed by characterising the simulated time series in this way. The parameters derived can be used to determine the areas of potential impact on wetland ecosystems due to changes in groundwater dynamics.

The simulated time series, as well as the duration curve at specific nodes on a transect perpendicular to the Elbe, showed the biggest changes in groundwater dynamics close to the position assumed for the relocated embankment (Fig. 5). Even far behind this relocated embankment an influence on groundwater dynamics could be observed. The main changes are related to increased infiltration during flood periods through the expanded area of flooding resulting from the relocated embankment. For low water periods, there were no significant changes. Similar observations were made (Fig. 6) by calculating the key statistics of groundwater levels, such as the highest high water level HHW, mean high water level MHW, mean water level MW, mean low water level MLW, lowest low water level LLW, along this transect.

Spatial analyses of changes in groundwater dynamics were achieved by calculating the differences in the statistical parameters of the time series for the present situation and for the situation in the case of embankment relocation, for each node in the numerical model. Groundwater depth has to be considered to assess the impact of changes in groundwater dynamics on wetland ecosystems. Assuming a fixed surface topography, changes in groundwater depth are equal to changes in groundwater level calculated from the numerical model result. The areas affected could be delineated by analyses of changes in groundwater depth with positive numbers indicating reductions in groundwater depth.

Changes in maximum groundwater depth during dry periods were within the accuracy of the model. The biggest 


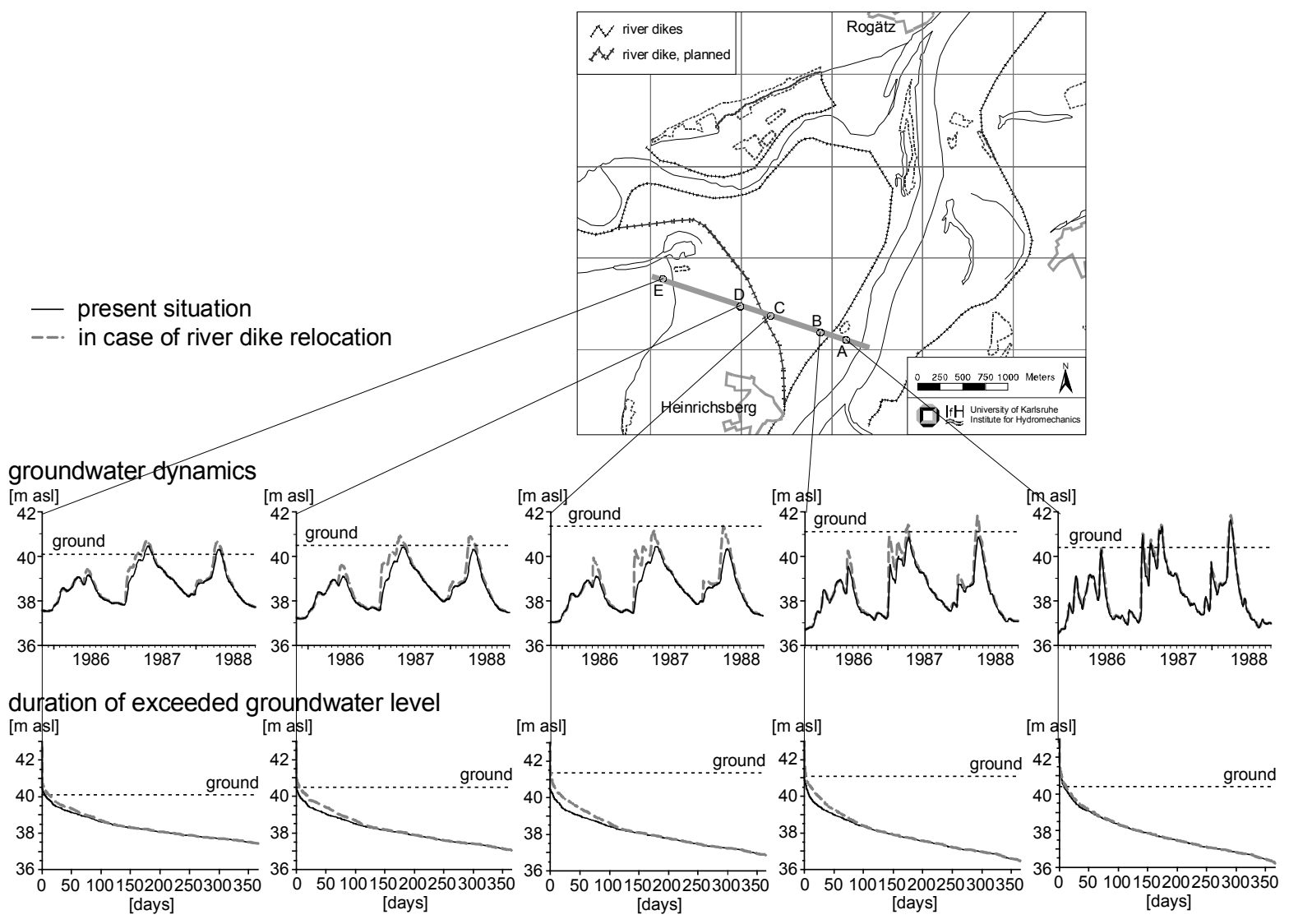

Fig. 5. Groundwater dynamics and derived duration curves at distinct locations on a transect perpendicular to the Elbe.
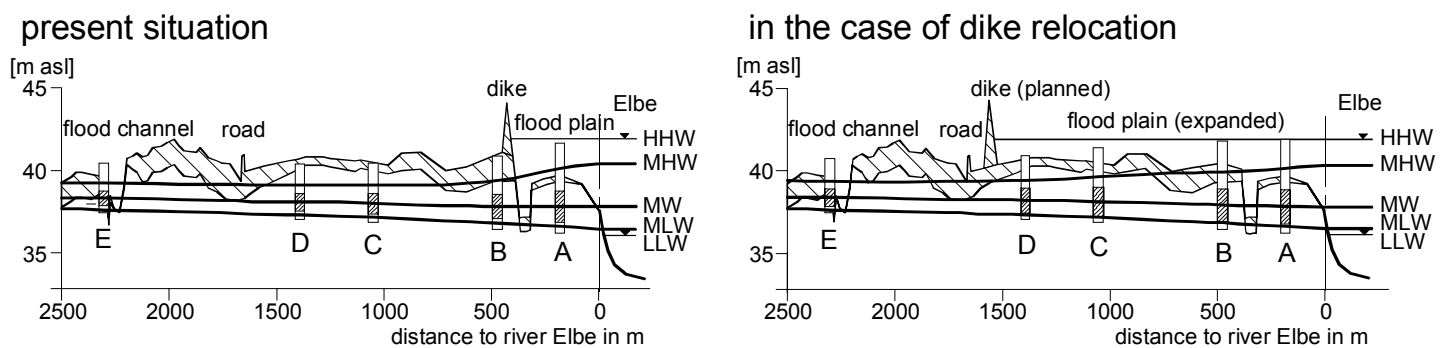

Fig. 6. Hydrologic principle values of groundwater levels along a transect perpendicular to the Elbe; HHW - highest high water level, MHW - mean high water level, MW - mean water level, MLW - mean low water level, LLW - lowest low water level.

changes in average and minimum groundwater depth occurred in the centre of the enlarged flood plain area (Fig. 7). Large areas behind the relocated embankment were also affected considerably. Changes in average groundwater depth were rather small. However, the considerable impact of embankment relocation on the groundwater depth dynamics was indicated by the bigger changes in the fluctuations of average groundwater depth compared to the changes in average groundwater depth itself. This impact was shown more clearly by considering changes in minimum groundwater depth; these exceeded the maximum value of changes in average groundwater depth, even far behind the embankments.

To assess the impact of changes in groundwater dynamics caused by embankment relocation on respective ecosystems, the changes predicted above have to be compared additionally with the absolute groundwater depth computed for the present situation. The average groundwater depth is an example of a very important physical variable describing habitat conditions. The computed absolute groundwater depth for the present situation was greater than $1.4 \mathrm{~m}$ in most parts of the study area (Fig. 8). The maximum predicted 
average groundwater depth

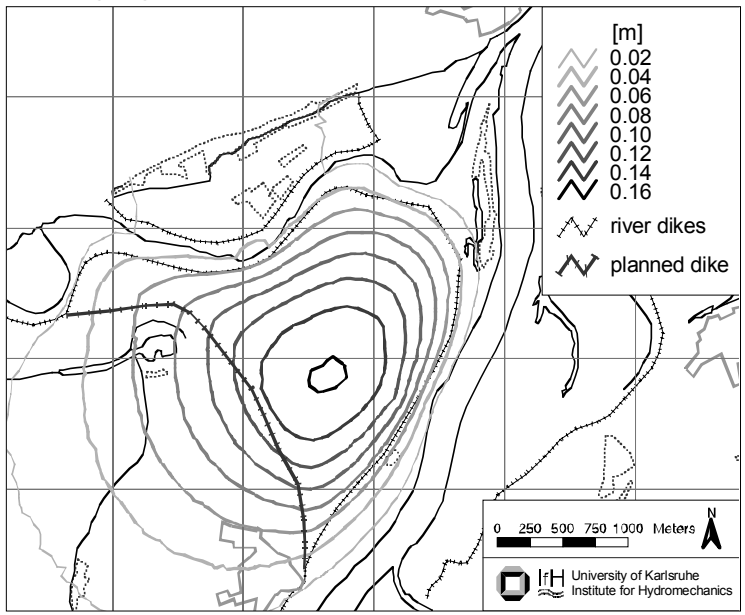

minimum groundwater depth

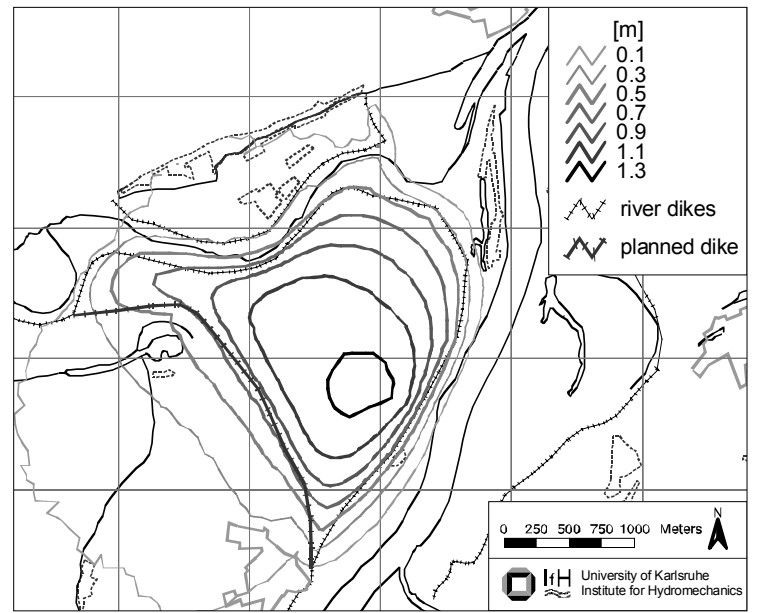

Fig. 7. Spatial distribution of changes in average and minimum groundwater depth.
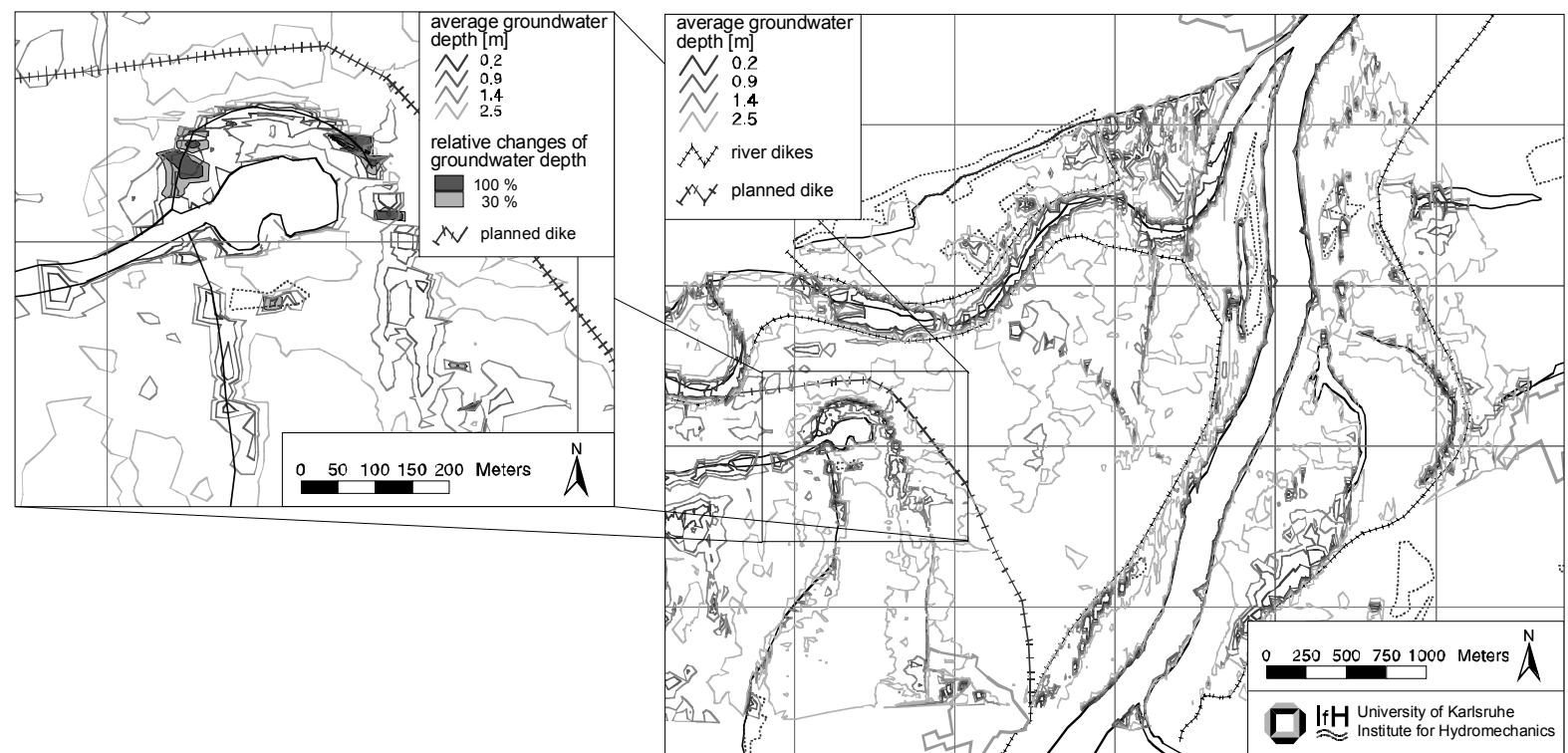

Fig. 8. Average groundwater depth and spatial distribution of areas with large relative changes.

changes in the same areas were about $0.17 \mathrm{~cm}$, which implies relative changes of less than $10 \%$ in those areas. These small changes should have only a minor effect on the local ecosystems. However, large relative changes were detected in a few areas (Fig. 8). There, embankment relocation could be expected to have apotential impact on the local ecosystem.

\section{Conclusions}

A new method is presented for predicting changes in groundwater dynamics caused by river embankment relocation by applying numerical groundwater modelling based on a physically based approach. Infiltration rates from intermittently inundated flood-plains were incorporated in the model by a leakage approach derived from the hydraulic properties of the soils within the flood plains. Thus, those infiltration rates were independent of model calibration in the case of flood plain expansion. The predictive capability of this method was demonstrated successfully for an area of the Elbe river valley north of Magdeburg. In the study area, the values of the aquifer parameter obtained by calibration of the groundwater flow model have been reasonable and similar to values from independent field studies. Therefore, this calibrated model could be used to predict changes in groundwater dynamics caused by river embankment relocation. 
The present groundwater dynamics over the 14-year period from November 1985 to October 1999, with the calibrated model, provided data for statistical analyses of the computed time series. The derived statistical parameters enabled the spatial characterisation of groundwater dynamics. The same analyses were undertaken for the predicted groundwater dynamics in the case of river embankment relocation. This prediction was based on the same boundary conditions, the same time period and model parameters except for the expanded flood plains. The prediction of future scenarios was not intended to distinguish effects of embankment relocation from those due to global changes in climate and hydrology. The changes in groundwater dynamics were quantified by comparison of the statistical parameters charaterising the present and the predicted groundwater dynamics. The impact of embankment relocation on groundwater dynamics is directly related to increased infiltration rates in the expanded floodplains during flood events. Therefore, larger changes were calculated for statistical parameters that are more affected by high water levels. Spatial analyses of the changes in groundwater dynamics revealed not only the strongest impact within the expanded flood-plain, but considerable impact far behind the relocated embankment.

In general, the method presented could be applied to any other study area, since the leakage parameter describing the soils within the flood plains is determined independently and the aquifer parameters can be obtained successfully by model calibration. Additionally, other physical factors affecting wetland ecosystems could be determined by further statistical analyses of the simulated time series, such as average duration of groundwater depth below a certain value. In this way, the method provides a tool for ecologists as part of a decision-support process to assess the impact of human activities, in particular embankment relocations, on wetland ecosystems with respect to changes in groundwater dynamics. For that purpose further investigations to develop simplified relations would avoid the necessity of setting up a detailed numerical groundwater flow model for each individual case. Those relations have to estimate the statistical parameters characterising groundwater dynamics directly from discharge time series. At the same time, they should consider all important parameters determining groundwater flow in a certain study area, such as aquifer parameters, boundary conditions and recharge. The method presented here, by providing a process-based tool for comparative purposes, could support similar investigations.

\section{Acknowledgement}

The research work was funded by the Federal Ministry of Education, Research and Technology (BMBF) as part of a joint project in the Elbe Ecology Research Programme. The author thanks the local and state authorities for providing data and supporting the field work.

\section{References}

Acreman, M., Harding, R., Lloyd, C. and McNeil, D., 2002. Comparison of evaporation from wet grassland and reed beds. Session HSA7, 27th General Assembly of the European Geophysical Society, Nice, France, Geophys. Res. Abs., 4 (CDROM).

Bates, P.D., Stewart, M.D., Desitter, A., Anderson, M.G., Renaud, J.-P. and Smith, J.A., 2000. Numerical simulations of floodplain hydrology, Water Resour. Res., 36, 2517-2529.

Blom, C.W., van de Steeg, H.M. and Voesenek, L.A., 1996. Adaptive Mechanisms of Plants Occurring in Wetland Gradients. In: Wetlands, G. Mulamoottil, B.G. Warner and E.A. McBean (Eds.), Lewis Publishers, Boca Raton. 91-112.

Jährling, K.-H., 1994. Moegliche Deichrückverlegungen im Bereich der Mittelelbe (Possible embankment relocations at the Middle-Elbe), Staatliches Amt fuer Umweltschutz, Magdeburg (in German).

Herrling, B., 1982. Finite element computations of horizontal groundwater flow with moving boundaries. In: Finite Elements in Water Resources, K.P. Holz, U. Meissner, W. Zielke, W. Brebbia, G. Pinder and W. Gray (Eds.), Springer, Berlin, Germany, 10.25-10.39.

Mohrlok, U., Eberhardt, E. and Jirka, G. H., 2000. Modelling groundwater recharge from intermittent flooded areas by calibration of time dependent leakage parameters. IAHS publication no. 265, Wallingford, UK, 509-514.

Saucke, U. and Brauns, J., 1999. Die Bedeutung strukturierter Sedimente im Hinblick auf Strömungsvorgänge und hydraulische Untergrundstabilität. In: Dynamik und Interaktion von Fluß und Aue, 4. - 7. Mai 1999, B. Buechele and S. Kiene, Fachtagung Elbe, , Wittenberge, Karlsruhe, 86-89 (in German).

Simunek, J., Vogel, T. and van Genuchten, M. Th., 1994. The SWMS_2D code for simulating water flow and solute transport in two-dimensional variably saturated media - Version 1.2. Research Report No. 132, Department of Agriculture, U.S. Salinity Laboratory, Riverside, California.

Rommel, J., 1998. Geologie des Elbetals nördlich von Magdeburg. Unpublished diplomathesis in Applied Geology, Geological Institute, University of Karlsruhe (in German).

Truebinger, E.-R., Salzmann, Th. and Miegel, K., 2002. Measurement and modelling of the saturated and unsaturated flow at wetlands. In: prepublished proceedings of ModelCARE'2002 conference, K. Kovar and Z. Hrkal (Eds.), Prague, Czech Republic, 585-588.

Weng, P., Fleury, P., Giraud, F. and Chevallier, C., 2002. Hydrological functioning of Rochefort marsh: from field measurements to numerical modelling. Session HSA7, 27th General Assembly of the European Geophysical Society, Nice, France, Geophys. Res. Abs., 4 (CD-ROM).

Winter, T.C., 1995. Recent advances in understanding the interaction of groundwater and surface water, Rev. Geophys., 33, 985-994. 